\title{
Mortality and morbidity after hip fractures
}

\author{
Graham S Keene, Martyn J Parker, Glyn A Pryor
}

Department of

Orthopaedic and Trauma

Surgery, Addenbrooke's

Hospital, Cambridge

CB2 2 QQ

Graham S Keene, career

registrar

\section{Department of}

Orthopaedic and Trauma

Surgery, Peterborough

District Hospital,

Peterborough PE3 6DA

Martin J Parker, research

registrar

Glyn A Pryor, consultant

surgeon

Correspondence to:

Mr Keene.

$B M 7$ 1993;307:1248-50

\section{Abstract}

Objective-To study the mortality and morbidity associated with proximal femoral fractures with reference to fracture type (intracapsular and extracapsular).

Design-Consecutive prospective study with 12 month follow ups.

Setting-Two British trauma receiving centres.

Patients-1000 consecutive acute proximal femoral fractures (fractured necks of femur) in 972 patients.

Results-Significantly higher mortality at one year was seen in patients with extracapsular fractures $(188 / 490 ; 38 \%)$ than in those with intracapsular fractures $(147 / 510 ; 29 \% ; p<0 \cdot 01)$. Greater morbidity was experienced during the study period by patients with extracapsular fractures, who were less mobile and less independent at the time of their injury.

Conclusions-The rise in average age of presentation with proximal femoral fracture is associated with a persistently high mortality $(33 \%)$ and morbidity, greater in patients with an extracapsular fracture. Comparison with other studies, principally from outside Britain, is difficult, but despite advancing standards of care the mortality and morbidity of femoral neck fractures remains high, placing an ever increasing burden on the health service.

\section{Introduction}

The incidence of proximal femoral fractures continues to rise and is approaching epidemic proportions, according to a report by the Royal College of Physicians in 1989'; such "femoral neck fractures" were estimated in 1987 to cost the NHS $£ 165$ million a year. ${ }^{2}$ Past mortality figures and morbidity measures have been circumspect and subject to much speculation, backed up with little substantiated evidence. ${ }^{3-5}$

\section{Assessing morbidity after fractured hip}

Mobility score-the mobility score is a point scoring system, previously published, ${ }^{3-5}$ for three basic functions:

- Can the patient do their own shopping?

- Is the patient able to get out of the house?

- Is the patient able to get about the house?

Each function is scored out of four points:

Able to do independently

On their own, but using an aid

Only with someone's assistance

Score 3 points

Score 2 points

Not able (bed, chair, or housebound)

Score 1 point

Score 0 points

Walking aids-Patients were questioned as to whether they could mobilise independently, with the use of sticks or a walking frame, or whether they considered themselves to be immobile.

Residential status-The residential status of patients before and after their fracture was considered in three categories: those living in their own home, those living in a residential or nursing home and those hospitalised (for 28 days or more).

Pain-Patients were assessed for the pain experienced and analgesia required at the end of the one year period:

Score 2 points Occasional and slight pain

Score 3 points Pain on initiation of exercise

Score 4 points Pain with exercise, not at rest

Score 5 points Constant yet bearable pain

Score 6 points Constant severe pain
We prospectively studied 1000 consecutive cases admitted to two centres with proximal femoral fractures to determine the level of mortality and morbidity, in relation to the type of fracture, with a one year follow up period after injury.

\section{Patients and methods}

One thousand consecutive admissions for proximal femoral fractures in 972 patients were prospectively studied. The patients were admitted in equal proportions to the Birmingham Accident Hospital and the Peterborough District Hospital between 1989 and 1992.

To determine morbidity, patients were assessed at the time of emergency admission. At regular intervals up to one year after their injury all surviving patients were reviewed in dedicated hip fracture clinics; those unable to attend the clinic were contacted by letter or telephone. Follow up was performed by one study member and all information was recorded on a computerised data base. For those patients who died, progress was monitored until the time of death.

Mortality is relatively easy to assess-only three patients could not be contacted or located, and inquiry to the Office of Population Censuses and Surveysconfirmed that they had not died. Morbidity, however, is less easy to quantify, and to measure morbidity, we studied four factors: mobility score; dependency on walking aids; residential status; and degree of residual pain (box). These factors were recorded for all patients immediately before their fracture and during the subsequent year. Statistical analysis was by the log rank test for the variable mortality and the MannWhitney $U$ test for pain and mobility. A $p$ value $>0.05$ was considered not significant.

\section{Results}

In 1000 cases of proximal femoral fractures there were 490 extracapsular fractures and 510 intracapsular fractures. Mean age at fracture was slightly higher in patients with extracapsular fractures ( 80 years) than in patients with intracapsular fractures ( 78 years). In both groups about $81 \%$ of patients were women. Intracapsular fractures included subcapital and transcervical fractures; extracapsular fractures included basal, trochanteric, pertrochanteric, and subtrochanteric fractures (within $5 \mathrm{~cm}$ of the lesser trochanter).

The patients admitted to the two hospitals were of similar characteristics: average age 79 years; $19 \%$ (94/ $500)$ of patients admitted to Peterborough District Hospital were male, compared with $18 \%$ (91/500) at Birmingham Accident Hospital; the average mobility scores before the accident $(5 \cdot 3)$ were identical for both hospitals; and 75\% (374) of patients at Peterborough District Hospital were admitted from their own home, compared to $71 \%$ (357) at Birmingham Accident Hospital.

Table I lists the methods of treatment. A minority of patients were treated conservatively: four patients with intracapsular fractures and 24 with extracapsular fractures were medically unfit for surgery. Conservative treatment was chosen as a preference for seven patients 


\begin{tabular}{lr}
\hline Method & $\begin{array}{c}\text { No of } \\
\text { patients }\end{array}$ \\
\hline Intracapsular fractures $(n=510):$ \\
Non-operative & 11 \\
Dynamic hip screw & 3 \\
Total hip replacement & 9 \\
Lag screws & 81 \\
Garden screws & 116 \\
Hemiarthroplasty & 290 \\
Extracapsular fractures $(n=490):$ \\
Non-operative & 42 \\
AO blade plate & 2 \\
Intramedullary nail & 15 \\
Nail plate & 35 \\
Dynamic hip screw & 396
\end{tabular}

with undisplaced intracapsular fractures and 18 with undisplaced extracapsular fractures. The method of conservative treatment for intracapsular fractures consisted of a period of bed rest to allow the pain to settle, followed by early mobilisation (partial or non-weight bearing). Patients with extracapsular fractures were treated with on average five weeks' skin traction followed by gentle mobilisation, non-weight bearing.

The remaining patients were treated surgically. Most intracapsular fractures within the Garden grades $\mathrm{I}$ and $\mathrm{II}^{\circ}$ were treated with internal fixation, and the more displaced fractures underwent hemiarthroplasty (Thompson or Austin Moore prosthesis). With a few exceptions, the extracapsular fractures were internally fixed with the AO/ASIF (Arbeitsgemeinschaft fur Osteosynthesefragen/Association for the Study of Internal Fixation) dynamic hip screw. Those patients given an intramedullary nailing device had sustained subtrochanteric fractures, all within $5 \mathrm{~cm}$ of the lesser trochanter.

\section{MORTALITY}

Mortality at one year was related to age and fracture type. Mortality was lowest in patients under $60(3 \%$; $2 / 56)$ and rose steadily to $51 \%(66 / 129)$ among the nonagenerians (fig 1). Mortality at six months and one year was significantly lower in patients with intracapsular fractures than those with extracapsular fractures (table II). Fifteen per cent of patients (152/1000) died during the study period without being discharged from hospital.

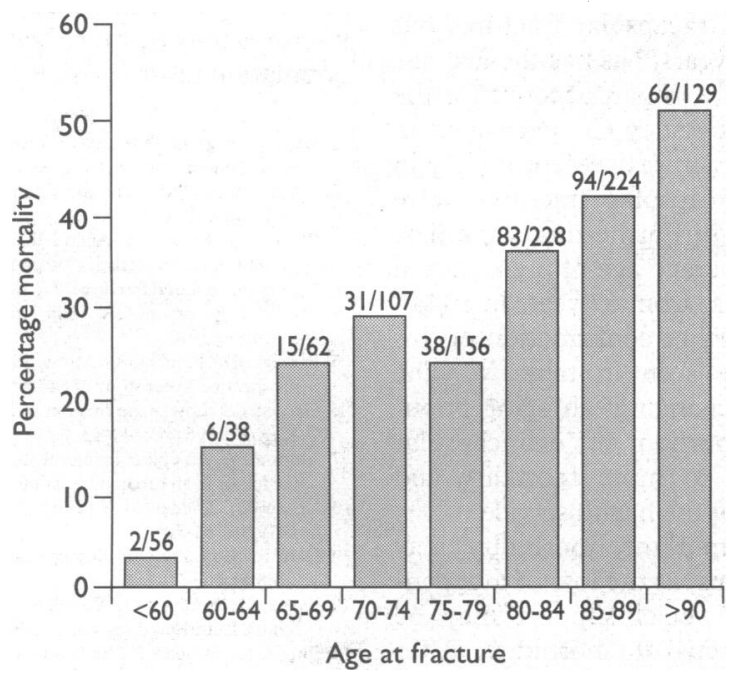

FIG 1-Mortality one year after proximal femoral fracture in relation to age

TABLE II-Mortality at six months and one year after proximal femoral fracture. Value are numbers (percentages) of patients unless indicated otherwise

\begin{tabular}{|c|c|c|}
\hline & $\begin{array}{l}\text { Mortality at } \\
6 \text { months }\end{array}$ & $\begin{array}{l}\text { Mortality at } \\
12 \text { months }\end{array}$ \\
\hline $\begin{array}{l}\text { All patients }(n=1000) \\
\text { Intracapsular fractures }\end{array}$ & $284(28)$ & $335(33)$ \\
\hline $\begin{array}{l}\text { Intracapsular fractures } \\
(n=510)\end{array}$ & $122(24)$ & $147(29)$ \\
\hline $\begin{array}{l}\text { Extracapsular fractures } \\
(n=490)\end{array}$ & $162(33)$ & $188(38)$ \\
\hline $\begin{array}{l}\text { Difference } \\
95 \% \text { Confidence interval (\%) } \\
\text { p Value for comparison }\end{array}$ & $\begin{array}{l}40(9) \\
3.6 \text { to } 14 \cdot 7 \\
<0.025\end{array}$ & $\begin{array}{l}41(9) \\
3.7 \text { to } 15.4 \\
<0.01\end{array}$ \\
\hline
\end{tabular}

TABLE III-Mobility scores (0-9) of survivors. Values are means (SD) unless indicated otherwise

\begin{tabular}{|c|c|c|c|c|c|}
\hline Score & $\begin{array}{l}\text { All patients } \\
(\mathrm{n}=716)\end{array}$ & $\begin{array}{c}\text { Intracapsular } \\
\text { fractures } \\
(n=388)\end{array}$ & $\begin{array}{c}\text { Extracapsular } \\
\text { fractures } \\
(n=328)\end{array}$ & $\begin{array}{c}\text { Difference } \\
\text { (95\% confidence } \\
\text { interval) }\end{array}$ & $\underset{\text { Value* }}{\mathbf{p}}$ \\
\hline $\begin{array}{l}\text { Before fracture } \\
\text { One year after fracture } \\
\text { Reduction in mobility }\end{array}$ & $\begin{array}{l}6 \cdot 0(2 \cdot 6) \\
4 \cdot 4(2 \cdot 2) \\
1.6(1.5)\end{array}$ & $\begin{array}{l}6 \cdot 2(2 \cdot 8) \\
4 \cdot 6(2 \cdot 7) \\
1 \cdot 6(1 \cdot 5)\end{array}$ & $\begin{array}{l}5 \cdot 7(2 \cdot 5) \\
4 \cdot 2(1 \cdot 8) \\
1 \cdot 5(1 \cdot 4)\end{array}$ & $\begin{array}{l}0.5(0.09 \text { to } 0.91) \\
0.4(0.05 \text { to } 0.75) \\
0.1(-0.12 \text { to } 0.32)\end{array}$ & $\begin{array}{l}0.006 \\
<0.001 \\
\text { NS }\end{array}$ \\
\hline
\end{tabular}

*Comparison of intracapsular and extracapsular fractures by Mann-Whitney $U$ test.
TABLE IV-Use of walking aids before and one year after fractured hip. Figures are numbers (percentages) of patients

\begin{tabular}{lcccc}
\hline & \multicolumn{4}{c}{ Aids used one year later } \\
\cline { 2 - 4 } & $\begin{array}{c}\text { No } \\
\text { aids }\end{array}$ & Sticks & $\begin{array}{c}\text { Zimmer } \\
\text { frame }\end{array}$ & Immobile \\
Walking before fracture & $144(40)$ & $122(34)$ & $85(23)$ & $11(3)$ \\
Unaided $(\mathrm{n}=362)$ & $2(1)$ & $83(44)$ & $95(51)$ & $8(4)$ \\
With sticks $(\mathrm{n}=188)$ & 0 & $1(1)$ & $61(76)$ & $19(23)$ \\
With Zimmer frame $(\mathrm{n}=81)$ & 0 & & &
\end{tabular}
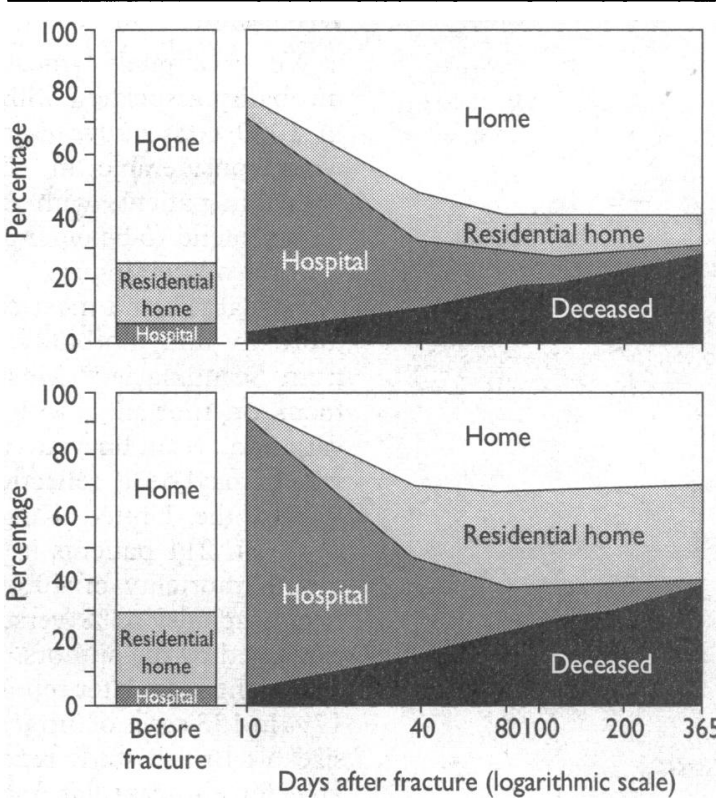

FIG 2-Residence of patients with intracapsular fractures (top) and extracapsular fractures (bottom)

MORBIDITY

Mobility-Patients with extracapsular fractures were less mobile than those with intracapsular fractures at the time of their injury. One year later, the extracapsular group continued to be less mobile but during the study period the loss of mobility was marginally greater in patients with intracapsular fractures (table III). Before their injury $28 \%$ of patients (284) were housebound; 46\% (305/665) were housebound after treatment. Similarly, $54 \%$ of patients (537) were able to do their shopping before their fracture, but only $33 \%$ (221) were able to go shopping one year later.

Walking aids-Both groups of patients showed a greater dependence on walking aids after one year (table IV). Of patients walking unaided before their fracture, $40 \%$ (144/362) returned to that state; $34 \%$ $(122 / 362)$ required sticks and $23 \%(85 / 362)$ a walking frame. Of those already using sticks before their fracture, $44 \%(83 / 188)$ returned to walking with sticks and $51 \%(95 / 188)$ required the use of a walking frame. Seventy six per cent $(61 / 81)$ of patients walking with a walking frame before their fracture still needed the device at one year. Only $1 \%(3 / 269)$ of those using either sticks or a walking frame improved on their previous mobility during the follow up period.

Residential status-The residential status required by patients with the two types of fracture varied greatly (fig 2). A greater proportion of patients with intracapsular fractures were living in their own home before injury $(76 \%(387 / 510) v 70 \%(344 / 490))$, and a year later a greater proportion of patients with intracapsular fractures had returned to living in their own home $(58 \%(298 / 510) v 28 \%(137 / 490))$. A total of $18 \%$ (93/510) of patients with intracapsular fractures were in residential accommodation at the time of injury, compared with $25 \%(121 / 490)$ of those with extracapsular fractures. After one year only $10 \%$ of patients with intracapsular fractures (50) required residential care, compared with $30 \%$ (149) of those with extracapsular fractures. 
Pain-The pain experienced by the two groups varied slightly. The patients with intracapsular fractures reported a mean (SD) residual pain score of $2.1(1.2)$ at one year compared with a score of 1.9 $(1.0)$ in patients with extracapsular fractures $(95 \%$ confidence interval of difference 0.03 to $0.37 ; p=0.02$, Mann-Whitney U test).

\section{Discussion}

We accurately measured the mortality and morbidity associated with proximal femoral fractures in 1000 consecutive cases. Mortality and morbidity were considerable in all patients but significantly higher in patients with extracapsular fractures-such patients tend to be older and have greater morbidity at the time of their injury.

The largest and most comprehensive studies on the mortality and morbidity of hip fractures have come from Scandinavia. ${ }^{7-9}$ Most previous studies (table V) focus on mortality, with rates showing considerable variation. Scandinavian mortality figures are lower, which may be a reflection of differing populations. Within the United Kingdom, a study from Newcastle on 211 patients in two hospitals reported a six month mortality of $40 \%$; the variation between the two hospitals, $53 \%$ versus $28 \%$, could not be fully explained by the authors. ${ }^{10} \mathrm{~A}$ further study in the same area eight years later reported a six month mortality of $17 \%$ in 158 cases of intracapsular fractures. ${ }^{11}$ The other sizeable British study reported a one year mortality of $26 \%$ for intracapsular fractures. ${ }^{12}$ There is evidence to suggest the proportion of extracapsular fractures has gradually increased over the years, ${ }^{13}$ as has the average age of the patients, which may in part account for the variable mortality figures. Sir Astley Cooper stated in 1824 that intertrochanteric fractures present mainly in the under $50 \mathrm{~s}$, while intracapsular fractures were predominant in "the elderly." ${ }^{14}$ Furthermore, the past five decades have seen the average age of presentation of hip fracture patients increase from 67 years in $1944^{15}$ to 79 years in this study. Further confirmation of this progressive age rise can be seen in table V. The pattern of disease is clearly changing; an aging population with a greater proportion of extracapsular fractures is bound to lead to more mortality and morbidity and greater costs for the health service.

Although mortality is important, morbidity may carry more serious implications, as the loss of independence and requirement for social support may be treatable-yet few papers focus on morbidity. After treatment, $80 \%$ of our surviving patients were discharged to their own home, and 55\% maintained this residential status after one year; the remainder had died or had moved to accommodation offering enhanced support. This compares with a study in 1983 that showed $50 \%$ of patients failed to return to their own home from hospital. ${ }^{16}$ It is difficult to

TABLE V-Mortality for all types of hip fractures

\begin{tabular}{|c|c|c|c|c|c|c|}
\hline \multirow[b]{2}{*}{ Study } & \multirow[b]{2}{*}{ Year } & \multirow[b]{2}{*}{ Country } & \multirow[b]{2}{*}{$\begin{array}{c}\text { No of } \\
\text { patients }\end{array}$} & \multirow[b]{2}{*}{$\begin{array}{c}\text { Average } \\
\text { age }\end{array}$} & \multicolumn{2}{|c|}{$\begin{array}{c}\text { Mortality } \\
(\%)\end{array}$} \\
\hline & & & & & $\begin{array}{c}6 \\
\text { Months }\end{array}$ & $\begin{array}{c}1 \\
\text { Year }\end{array}$ \\
\hline Fitts $e t a l^{20}$ & 1959 & USA & 109 & 71 & 24 & NA \\
\hline Alffram 5 & 1964 & Sweden & 1114 & 72 & 19 & NA \\
\hline Baker et al $P^{1}$ & 1978 & England & 50 & NA & 44 & NA \\
\hline Evans $e t a l^{\beta}$ & 1979 & England & 211 & NA & 40 & NA \\
\hline Jensen $e t a t^{6}$ & 1979 & Denmark & 1592 & 77 & 21 & 27 \\
\hline Ceder $e t a l^{2}$ & 1980 & Sweden & 103 & 75 & 10 & NA \\
\hline Dahl $^{7}$ & 1980 & Norway & 675 & 74 & 21 & NA \\
\hline Kenzora et $a l^{3}$ & 1984 & USA & 406 & 74 & NA & 14 \\
\hline Kreutzfeldt et al ${ }^{24}$ & 1984 & Denmark & 117 & 79 & NA & 26 \\
\hline White et a ${ }^{25}$ & 1987 & Canada & 272 & 75 & NA & 22 \\
\hline Dolk $^{26}$ & 1989 & Sweden & 282 & NA & NA & 28 \\
\hline Present study & 1993 & England & 1000 & 79 & 28 & 33 \\
\hline
\end{tabular}

$\mathrm{NA}=$ Not available.

\section{Clinical implications}

- The average age of presentation with a proximal femoral fracture has continued to rise

- The proportion of extracapsular fractures has increased

- Over half of patients retain their former residential status one year after their fracture

- Mortality and morbidity are higher in patients with extracapsular fractures

- As the population ages, proximal femoral fractures will place an increasing burden on the health service

determine to what extent the loss of independence following a hip fracture is related to the injury, although all patients had a loss of mobility. Many of the patients who moved into a residential home had already considered such housing, and the fracture served as a catalyst. Although intracapsular fractures were more painful, chronic pain did not seem to be an important factor after a proximal femoral fracture.

This paper identifies the considerable morbidity and mortality attached to proximal femoral fractures, together with the potential social implications, and highlights the need to reduce the incidence of femoral neck fractures. Recently the use of hormone replacement therapy has been emphasised, but efforts to prevent the falls that generally precipitate such fractures may be more beneficial for the current elderly population most at risk. ${ }^{17-19}$

1 Royal College of Physicians. Fractured neck of femur; prevention and management. London: Associated Book Publishers, 1989

Wallace WA. The scale and financial implications of osteoporosis. Int Med 1987; suppl 12:3-4.

3 Parker MJ, Pryor GA, Anand JK, Lodwick R, Myles JW. A comparison of presenting characteristics of patients with intracapsular and extracapsular proximal femoral fractures. $f R$ Soc Med 1922;85:152-5.

4 Parker MJ, Pryor GA. Hip fracture management. Oxford: Blackwell Scientific, 1993.

5 Parker MJ, Pryor GA, Myles JW. Early discharge after hip fracture: a prospective 3 year study of 645 patients. Acta Orthop Scand 1991;62:563-6.

6 Garden RS. Low angle fixation of fractures of the femoral neck. $\mathcal{F}$ Bone foint Surg $[B r]$ 1961;43:647-63.

7 Alffram PA. An epidemiological study of cervical and trochanteric fractures of the femur in an urban population. Acta Orhop Scand 1964;suppl 65.

8 Jensen JS, Tondevold E. Mortality after hip fractures. Acta Orthop Scand 1979;50:161-7.

9 Dahl E. Mortality and life expectancy after hip fractures. Acta Orthop Scand 1980;51:163-70.

10 Evans GJ, Prudham D, Wandless I. A prospective study of fractured proximal femur: factors predisposing to survival. Age Ageing 1979;8:246-50.

11 Ions GK, Stevens J. Prediction of survival in patients with femoral neck fractures. F Bone foint Surg [Br] 1987;69:384-7.

12 Skinner PW. Displaced subcapital fractures of the femur: which operation f Bone foint Surg [Br] 1988;70:677.

13 Zain Elabdien BS, Olerud S, Karlstrom G, Smedby B. Rising incidence of hip fracture in Uppsala, 1965-1980. Acta Orthop Scand 1984;55:284-9.

14 Cooper A. Fractures of the upper part of the thigh bone. In: $A$ treatise of dislocation and on fractures of the joints. 3rd ed. London: Longman, 1824:108.

15 Linton P. On the different types of fractures of the neck of femur. Acta Chir Scand 1944;suppl 86.

16 Melton LJ, Riggs BL. Epidemiology of age-related fractures. In: Avioli LV, ed. The osteoporotic syndrome. New York: Grune and Stratton, 1983.

17 Livesley B. Reducing home accidents in elderly people. BMf 1992;305:2-3.

18 Thomas TG, Stevens RS. Social effects of fractures of the neck of the femur. $B M \mathcal{A} 1974$;ii:456-8.

19 Graham HJ, Firth J. Home accidents in older people: role of primary health care team. $B M \Im$ 1992;305:30-2.

20 Fitts WT, Lehr HB, Schor S, Roberts B. Life expectancy after fracture of the hip. Surg Gynecol Obstet 1959;108:7-12.

21 Baker BR, Duckworth T, Wilkes E. Mental state and other prognostic factors in femoral fractures of the elderly. $\mathcal{F} R$ Coll Gen Pract 1978;28:557-9.

22 Ceder L, Thorngren K-G, Wallden B. Prognostic indicators and early home rehabilitation in elderly patients with hip fractures. Clin Orhop 1980;152: $173-84$

23 Kenzora JE, McCarthy RE, Lowell JD, Sledge CB. Hip fracture mortality, relation to age, treatment, preoperative illness, time or surgery, and complications. Clin Orthop 1984;186:45-56.

24 Kreutzfeldt J, Haim M, Bach E. Hip fracture among the elderly in a mixed urban and rural population. Age Ageing 1984;13:111-9.

25 White BL, Fisher WD, Laurin CA. Rate of mortality for elderly patients afte fracture of the hip in the 1980's. F Bone foint Surg [Am] 1987;69:1335-40.

26 Dolk $\mathrm{T}$. Influence of treatment factors on the outcome after hip fractures. Ups $\mathcal{F}$ Med Sci 1989;94:209-21. 